\title{
High-Temperature Stress Relaxation Cracking and Stress Rupture Observed in a Coke Gasifier Failure
}

\author{
Daniel J. Benac • Douglas B. Olson • \\ Michael Urzendowski
}

Submitted: 13 September 2010/Published online: 7 December 2010

(c) ASM International 2010

\begin{abstract}
This article discusses the high-temperature metal degradation mechanisms that occurred in the failure of a nine-story tall coke gasifier, located in a refinery power plant. Cracking of gasifier internals, bulging and stress rupture of the vessel shell, and escape of hot syngas resulted in an external fire. The failure mechanisms include stress relaxation cracking of a large diameter Incoloy Alloy 825 tube, stress rupture of the 4.65 -in. thick, $1 \frac{1}{4}$ chromium steel shell wall, and oxidation of $1 \frac{1}{4}$ chromium steel exposed to hot syngas. The gasifier process and operating conditions that contributed to the high-temperature degradation will be discussed.
\end{abstract}

Keywords Coke gasifier - Stress rupture ·

Reheat cracking · Stress relaxation cracking - Incoloy 825

\section{Introduction}

This article discusses the failure of a pressure vessel wall and internal components that resulted in an external fire at a nine-story tall coke gasifier, located in a refinery power plant. After the fire, investigators found that the 4.65-in. thick shell of the gasifier had bulged and ruptured. This rupture allowed hot syngas to escape, causing the fire. After

This article is an invited paper selected from presentations at MS\&T 2010, held October 18-20, 2010, in Houston, Texas, and has been expanded from the original presentation.

D. J. Benac $(\bowtie) \cdot$ D. B. Olson

Baker Engineering and Risk Consultants, San Antonio, TX, USA

e-mail: dbenac@bakerrisk.com

M. Urzendowski

Valero Energy, San Antonio, TX, USA the incident, a section of the vessel wall spanning the area where the shell failure occurred was cut out to allow internal inspection. A large irregular hole was found in the dip tube, an annular tube inside the vessel conducting the hot gas flow to a water quench. An investigation was performed to identify possible scenarios for the cause of the incident.

\section{Gasifier Design and Operation}

The refinery power plant had two gasifiers, shown in Fig. 1, each with two stages; an upper, refractory-lined combustion chamber and a lower water quench chamber. The gasifier feed is a high concentration water slurry of petroleum coke containing minor additives. This slurry is injected into the top of the gasifier where it reacts with oxygen at high pressure and temperature, producing synthesis gas (syngas), a mixture of hydrogen, carbon monoxide, carbon dioxide, water vapor, and minor components. At the time of the incident, the coke feed rate was 900 tons/day.

During startup of a gasifier, the combustion chamber is preheated to a temperature $>1,040{ }^{\circ} \mathrm{C}$ using a fuel-air burner operating slightly above atmospheric pressure. During normal operation, the gasifier pressure is much higher, ranging from 700 to 1,000 psig. On the day of the incident, the gasifier operating pressure was about 730 psig. Reaction temperatures are moderated by the water in the slurry to a typical range of $1,300-1,500{ }^{\circ} \mathrm{C}$. At these temperatures, the noncombustible residue from the slurry is a molten slag, which flows along with the syngas out the bottom of the gasifier combustion chamber into a quench chamber. The syngas and slag are rapidly cooled in a water bath contained in the quench chamber which also serves to separate the syngas from the slag. The syngas 


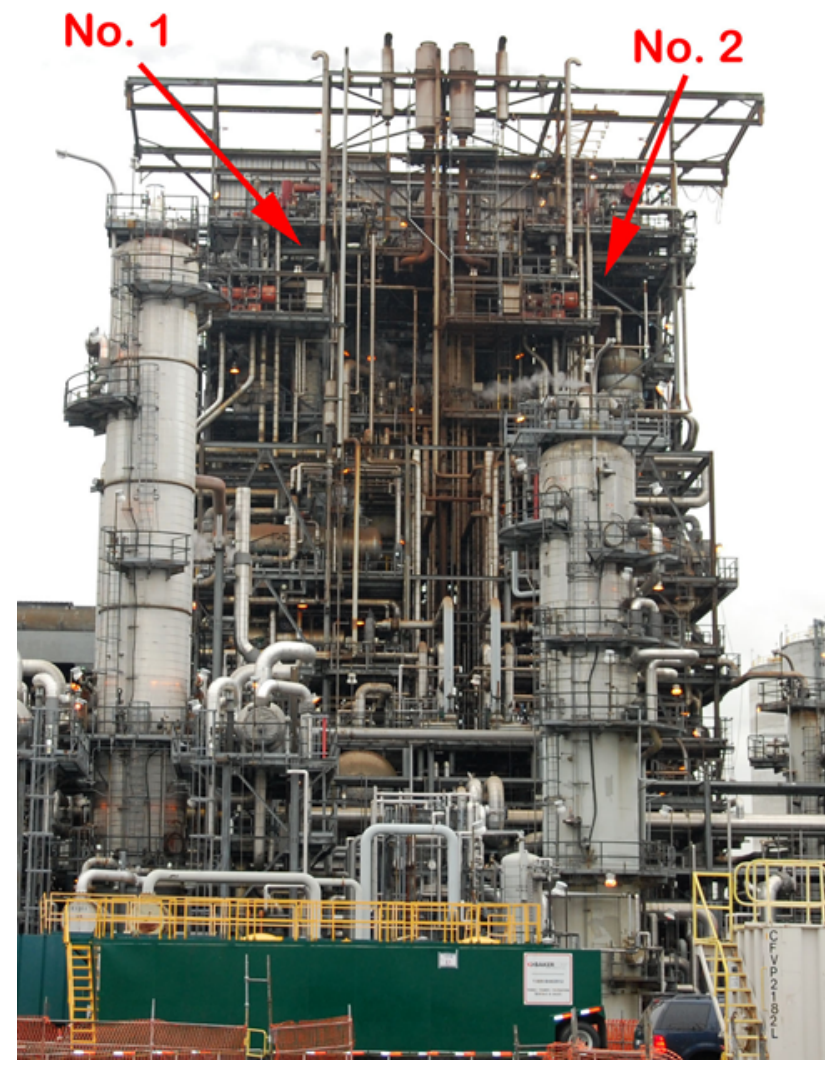

Fig. 1 Gasifiers no. 1 and no. 2. The gasifier no. 1 rupture occurred on the seventh story of the nine-story gasifier

exits the gasifier and flows through additional stages of scrubbers.

Figure 2 shows a simplified flow diagram for the gasifier and scrubber. The syngas with entrained slag exited the combustion chamber through two concentric tubes, called the dip tube (inner) and the draft tube (outer), which were submerged at their lower end in the quench water. Because of the presence of water and since the draft tube is longer than the dip tube, the gas flow through the dip tube is directed into the annulus between the two tubes. A mixture of syngas and water flow upward in this annulus, cooling the gas and the wall of the dip tube.

The gasifier vessel had a fiber optic system mounted on the outer wall of the combustion chamber to monitor its skin temperature and to alarm if the skin temperature exceeded $315^{\circ} \mathrm{C}$. This temperature sensing system, however, was not in service at the time of the incident. The quench chamber temperature was measured by one thermocouple, located in the upper part of the chamber outside the draft tube.

\section{Gasifier History and Modifications}

The syngas temperature exiting the combustion chamber is too high for long-term service of the metal dip tube without cooling. Therefore, the inner surface of the dip tube was cooled by a water film injected via a quench ring located concentric to the combustion chamber exit orifice. The gasifier vessel wall of the quench chamber was not refractory lined; in fact it was insulated to reduce heat losses. To improve throughput, the configuration of the dip and draft tubes had been modified with the addition of a top hat design, intended to turn the gas/water flow downward. In the original design, the top of the draft tube was about $11 \mathrm{in}$. below the quench ring on the combustion chamber exit. In the top hat configuration, its top was about $40 \mathrm{in}$. below the quench ring. In the original design, the upper part of the dip tube was cooled on the inside by a water film and on the outside by splashing of the quench water. The gasifier had operated for about $3,000 \mathrm{~h}$ after the top hat modification was made before the incident.

\section{Operating Conditions}

After the incident, the process operating data were reviewed. Syngas temperatures were measured downstream of the combustion chamber at two locations: at an upper region of the quench chamber on the west side under the cone and behind baffles and gussets, and in the gasifier syngas outlet line. The gasifier outlet probe did not show an abnormal temperature, but this probe was located in the outlet downstream of a water spray, which may have masked any change in operating condition.

The data from the other probe showed that the quench chamber temperature had exceeded its normal operating temperature of about $230{ }^{\circ} \mathrm{C}$ during the day of the incident. Reviewing past process data showed that the quench chamber temperature had also exceeded its normal range when the gasifier had last been operated (gasifier no. 1 had been out of service for some time). Excursions of $80-110{ }^{\circ} \mathrm{C}$ above the normal operating temperature had been measured for about $8.5 \mathrm{~h}$; the highest measured temperature was $310^{\circ} \mathrm{C}$. On another day of operation, the temperature was above normal for about $4.5 \mathrm{~h}$; the highest measured temperature on that day was $360{ }^{\circ} \mathrm{C}$. The total duration of gasifier operation with an elevated quench chamber temperature was about $13 \mathrm{~h}$. As the quench chamber temperature probe was not located directly in the syngas flow or in the region where the vessel wall failure occurred, the local temperature on the east side of the dip tube where the failure occurred was actually hotter than indicated.

\section{On-Site Damage Assessment}

After the fire was extinguished, the gasifier was examined. The vessel shell was bulged and had ruptured on the east 


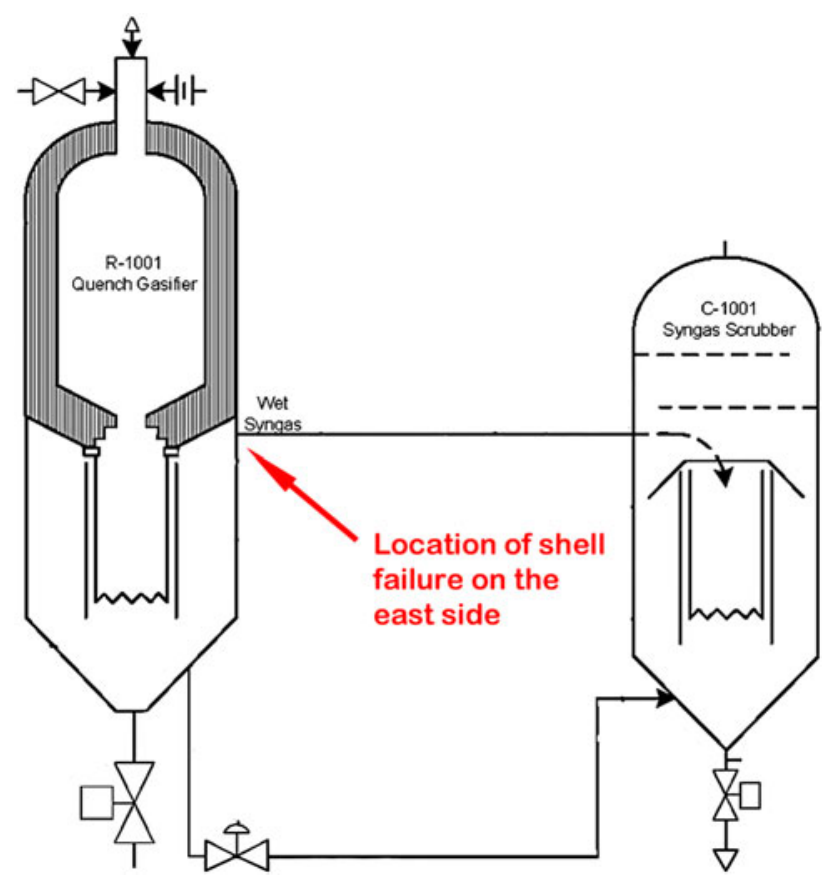

Fig. 2 Simplified illustration of the gasifier and scrubber. The rupture occurred on the east side of the shell in the quench chamber wall

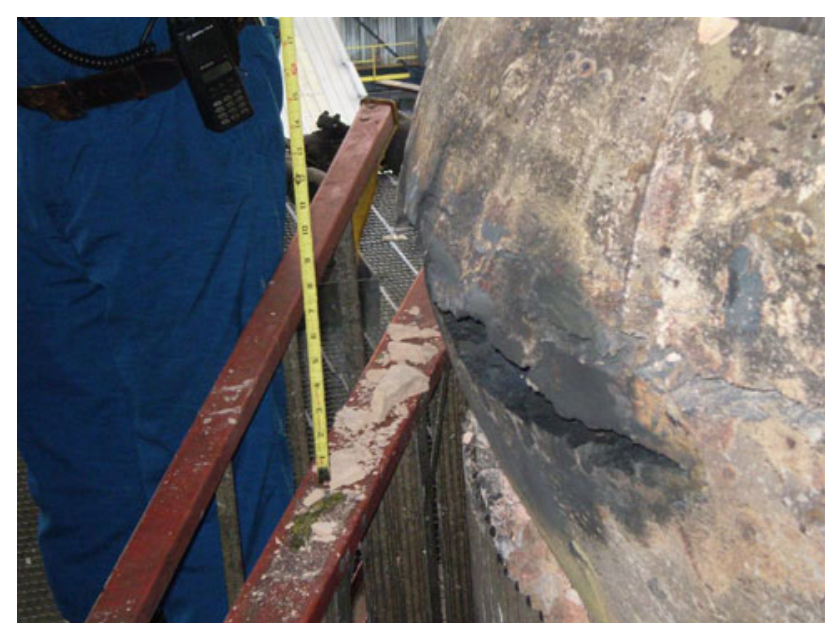

Fig. 3 Gasifier vessel rupture on the east side

side at the seventh deck level. Figure 3 shows the rupture from the south, which was $17 \mathrm{in}$. below the transition from the combustion chamber to the quench chamber. The rupture allowed hot gas to escape, and a fire occurred on the deck. The following field observations of the physical condition of the gasifier were made during the on-site investigation.

\section{Gasifier Shell Conditions}

The gasifier shell wall material was $1 \frac{1 / 4}{4} \mathrm{Cr}-1 / 2$ Mo (A387 Grade 11 Class 2), clad with Type 316 stainless steel on its

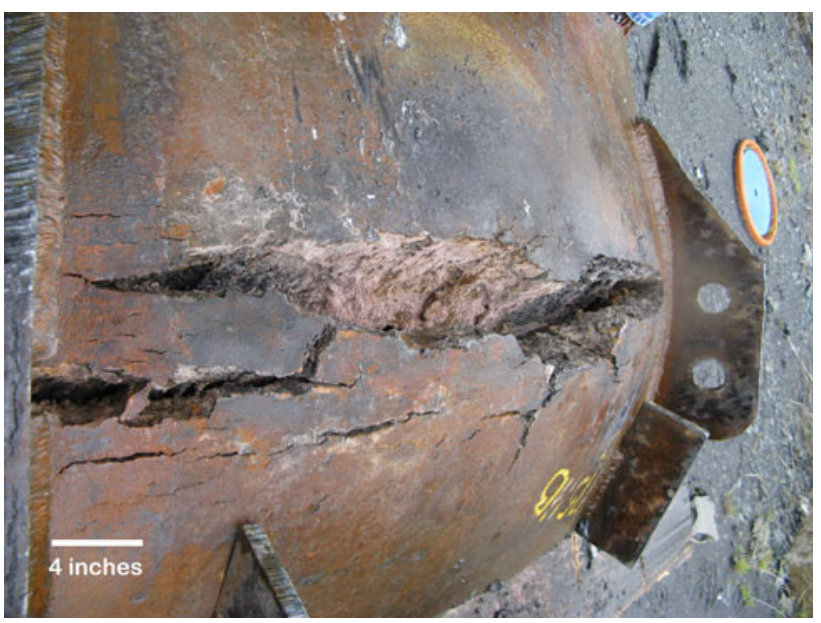

Fig. 4 Horizontal cracks on the exterior of the gasifier shell wall

inside surface. The 4-7/16-in. thick vessel had localized bulging and horizontal (transverse) cracking on its east side at the seventh deck level. The shell was bulged outward about 8 in. The cracking extended about 40 in. horizontally, as shown in Fig. 4. A horizontal fracture is not the typical mode of failure for a pressure vessel subjected to internal overpressure. Usually, the fracture would be in the vertical (axial) plane. Therefore, the horizontal fracture indicated that there had been combined bending and thermal stresses that contributed to causing the fracture.

The fracture initiated from the outside surface, indicative of bending, thermal, and internal pressure stresses. As the fracture initiated from the outside surface rather than from the inside surface, the failure was not caused by a condition on the inside surface of the shell, such as corrosion or hydrogen attack. Multiple cracks on the outer surface indicated that cracking occurred as the vessel wall gradually yielded, probably due to localized overheating while under pressure. This type of shell failure is classified as a creep failure and will be discussed in this article.

\section{Quench Chamber Internal Condition}

To examine the internal condition of the gasifier, an abrasive water jet was used to cut out a plate from the shell, spanning the area where the shell failure occurred. The cone plate that separated the combustion and quench chambers was burned away in this area, as were several baffles and supports, Fig. 5. A large irregular hole was found on the east side of the dip tube wall above the top hat, shown in Fig. 6. The hole had allowed hot syngas to bypass the water quench, and a considerable quantity of solid material had deposited outside the dip tube on the top hat and the water lines feeding the quench ring. The dip tube was extensively distorted and buckled above and 


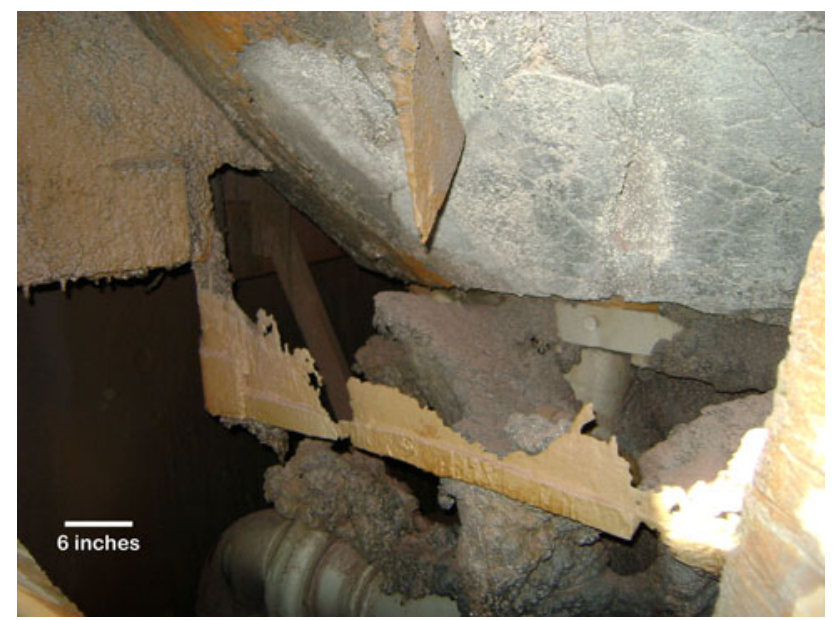

Fig. 5 Burned away cone plate and baffle, also showing deposits on the quench lines. The cone plate that should be in the upper right-hand part of the photograph is burned away, exposing the castable refractory that was above it. Notice the material build-up on the water-cooled quench lines

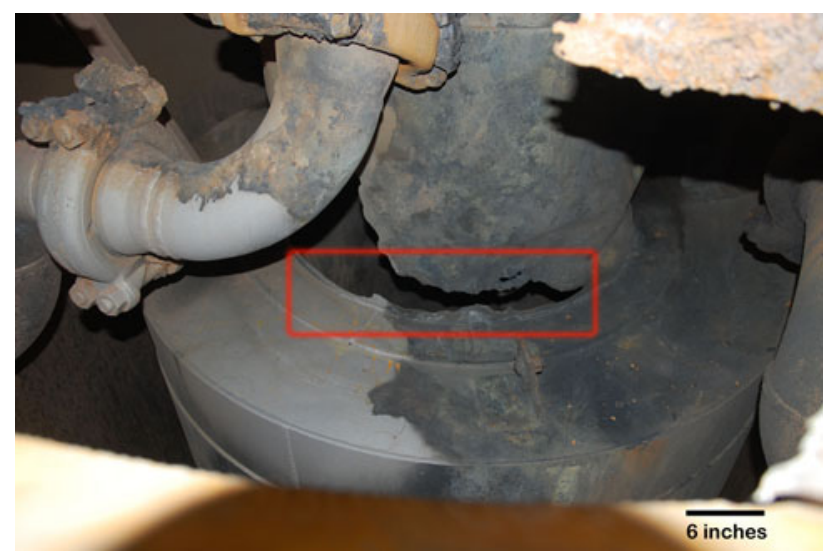

Fig. 6 Large irregular hole on the east side of the dip tube. Photograph taken after the material build-up was removed. The outline shows the location of the elongated hole that resulted from the fracture above the top hat

below the top hat, and there were through-wall cracks and holes at isolated locations above the top hat. Horizontal and vertical cracks were observed on the west side of the dip tube, located above the top hat, as shown in Fig. 7.

\section{Metallurgical Analysis and Damage Assessment}

Several analyses and metallurgical assessments were performed to investigate possible scenarios for the cause of the incident. The dip tube, shell wall, and cone plate from were sectioned and examined. Tests included chemical composition, tensile testing on the dip tube, hardness testing on selected samples, and examination of microstructures. In addition, deposit and scale samples were analyzed using

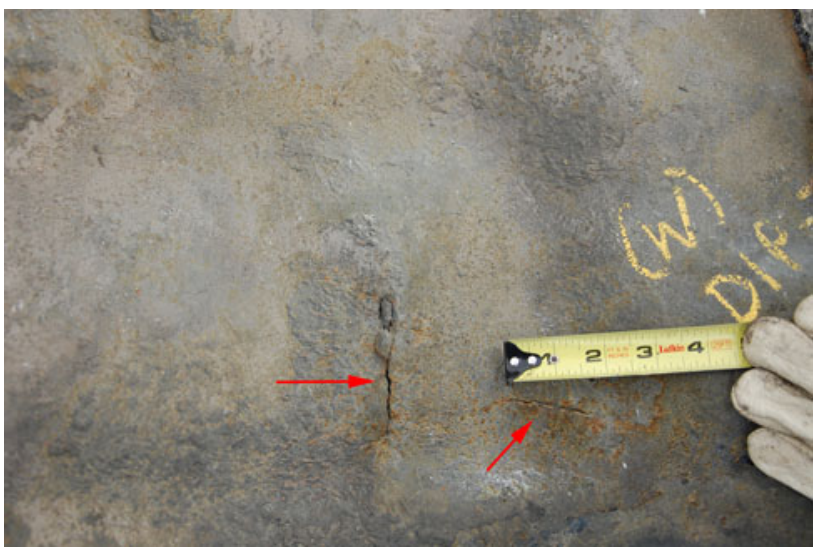

Fig. 7 Cracks on the west side of the dip tube above the top hat, viewed from inside

X-ray diffraction (XRD) to identify the compounds present.

\section{Gasifier Materials of Construction}

The materials of construction for items examined during the incident investigation are shown in Table 1. Incoloy Alloy 825 was used for the dip tube because of its resistance to carbonic and formic acid corrosion.

Table 2 shows the chemical composition of samples removed from the vessel shell and the cone plate (the plate separating the combustion and quench chambers, and supporting the refractory at the bottom of the combustion chamber). Chemical analysis was performed using optical emission spectroscopy. Carbon and sulfur testing was performed by the combustion method.

The chemical composition for shell plate satisfied the requirements of SA 387 Grade $11\left(1 \frac{1 / 4}{\mathrm{Cr}-1 / 2} \mathrm{Mo}\right)$. The carbon content on the cone was slightly higher than the material specification, but that could be explained since the cone had been exposed to elevated temperature and hot carbon-containing gases for extended periods of operation. Other than the higher carbon content, the cone satisfied the requirements of SA 387 Grade $11\left(1 \frac{1}{4} \mathrm{Cr}-1 / 2 \mathrm{Mo}\right)$.

Table 3 shows the test results for a sample of the dip tube. The dip tube sample satisfied the chemical composition requirements for Incoloy 825 .

\section{Composition of Material Deposits}

Material deposits from the top hat and the quench lines on the east side of the outside of the dip tube, Fig. 5, were analyzed. Figure 8 shows a sample that was removed from a quench line near the rupture. Three samples were analyzed using a positive material identification (PMI) 
Table 1 Material of construction of selected gasifier components

\begin{tabular}{|c|c|}
\hline Item & Material of construction \\
\hline Gasifier vessel shell wall & $\begin{array}{l}\text { 4-7/16-in. thick, } 1 \frac{1 / 4}{\mathrm{Cr}-1 / 2} \text { Mo steel (ASTM SA-387 Grade } 11 \text {, Class } 2 \text { ) steel } \\
\text { with interior Type } 316 \text { stainless steel cladding } 3 \mathrm{~mm} \text { overlay }\end{array}$ \\
\hline $\begin{array}{l}\text { Cone plate separating combustion chamber } \\
\text { from quench chamber }\end{array}$ & 1-in. thick, $1 \frac{1 / 4}{\mathrm{Cr}-1 / 2}$ Mo steel (ASTM SA-387 Grade 11, Class 2) \\
\hline Quench ring & Incoloy 825 , nickel-iron-chromium alloy \\
\hline Dip tube & 1/4-in. thick tube, Incoloy 825 , nickel-iron-chromium alloy \\
\hline Draft tube & 1/4-in. thick, Type 316 stainless steel \\
\hline \multirow[t]{2}{*}{ Refractory lining of combustion chamber interior } & Wall: dense chromia-alumina brick \\
\hline & Cone region: dense high chromia brick \\
\hline Castable refractory beneath brick in contact with cone plate & Dense alumina \\
\hline
\end{tabular}

Table 2 Chemical analysis results for the shell and cone (wt.\%)

\begin{tabular}{llll}
\hline Sample/element & Shell & Cone & SA 387 Grade 11 \\
\hline Carbon & 0.15 & 0.25 & $0.05-0.17$ \\
Manganese & 0.46 & 0.56 & $0.35-0.73$ \\
Phosphorus & 0.010 & 0.008 & $0.035 \mathrm{Max}$ \\
Sulfur & 0.004 & 0.002 & $0.040 \mathrm{Max}$ \\
Silicon & 0.56 & 0.50 & $0.44-0.86$ \\
Chromium & 1.31 & 1.32 & $0.94-1.56$ \\
Nickel & 0.08 & 0.23 & N/R \\
Molybdenum & 0.56 & 0.52 & $0.40-0.70$ \\
Copper & 0.14 & 0.23 & N/R \\
Iron & Balance & Balance & Balance \\
\hline
\end{tabular}

$N / R$ not required

Table 3 Chemical analysis results for the dip tube (wt.\%)

\begin{tabular}{lcc}
\hline Sample/element & Dip tube & $\begin{array}{c}\text { Typical composition } \\
\text { ASTM B424 }\end{array}$ \\
\hline Carbon & 0.02 & $0.05 \mathrm{Max}$ \\
Manganese & 0.42 & $1.0 \mathrm{Max}$ \\
Phosphorous & 0.018 & $0.03 \mathrm{Max}$ \\
Sulfur & $<0.001$ & $0.03 \mathrm{Max}$ \\
Silicon & 0.36 & $0.5 \mathrm{Max}$ \\
Chromium & 21.69 & $19.5-23.5$ \\
Nickel & 42.22 & $38.0-46.0$ \\
Molybdenum & 3.46 & $2.5-3.5$ \\
Copper & 1.70 & $1.5-3.0$ \\
Aluminum & 0.10 & $0.2 \mathrm{Max}$ \\
Titanium & 1.02 & $0.6-1.2$ \\
Iron & Balance & $22.0 \mathrm{~min}$ \\
\hline
\end{tabular}

analyzer at the plant. It was determined that the material was magnetic and predominantly iron (95\%), with minor amounts of titanium (1.2\%), chromium $(0.70 \%)$, and lesser amounts of molybdenum, vanadium, copper, and manganese. The magnetic property of the material and the large percentage of iron indicate that the material was

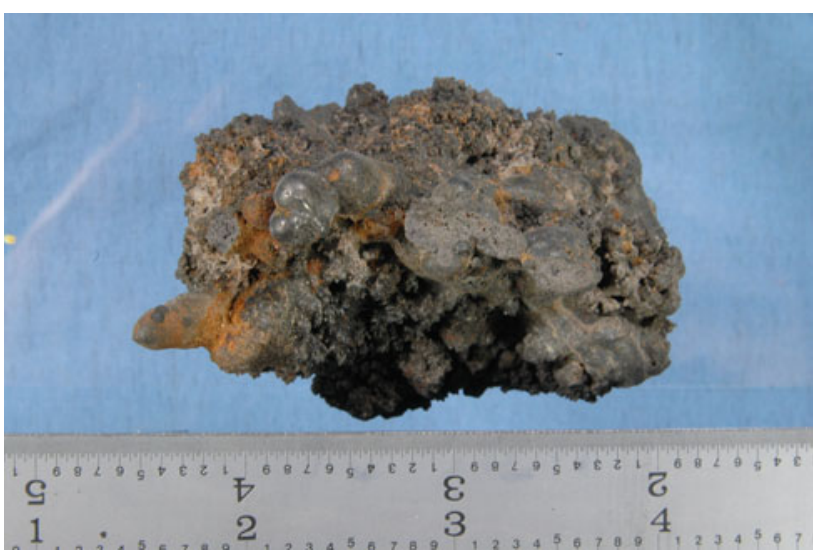

Fig. 8 Material found on the quench lines

mainly from the iron-chromium-molybdenum cone plate. The magnetic tendency of the product indicated that metallic iron was present.

Several deposits were analyzed using energy dispersive X-ray spectroscopy (EDS) and XRD. EDS was used to identify what elements were present, and XRD was used to identify what compounds were present. Table 4 shows the EDS and XRD results for the slag material inside the gasifier and material found on the quench lines. XRD analysis of the material from the quench line revealed the presence of iron and chromium oxides and sulfides. These are the by-products of oxidation and sulfidation of the cone material. The material had oxidized and probably melted, causing the material to drip onto the quench line. Contrary to what was initially suspected, the quench line deposit was not residual slag from the inside of the dip tube; it was degraded cone plate material.

\section{Dip Tube Failure Analysis}

To evaluate the dip tube failure, a $360^{\circ}$ section about 2 feet above the top hat was removed, sectioned, and examined. 
Table 4 X-ray diffraction test results

\begin{tabular}{|c|c|}
\hline Sample description & Compounds indentified \\
\hline Slag material from inside of gasifier & $\begin{array}{l}\text { Chromium, iron, nickel, } \mathrm{Ni}-\mathrm{Cr}-\mathrm{Fe} \text {; augite }(\mathrm{Ca}, \mathrm{Mg}, \mathrm{Fe}, \mathrm{Al})(\mathrm{Si}, \mathrm{Al})_{2} \mathrm{O}_{6} \text {; magnetite, } \mathrm{Fe}_{3} \mathrm{O}_{4} \\
\text { chromite, } \mathrm{FeCr} \mathrm{O}_{4} ; \text { diopside, } \mathrm{CaMg}\left(\mathrm{SiO}_{3}\right)_{2} ; \text { magnesium vanadium oxide, } \mathrm{Mg}_{1.5} \mathrm{VO}_{4} ; \\
\text { vanadium oxide, } \mathrm{VO}_{0.53} ; \text { karelianite, } \mathrm{V}_{2} \mathrm{O}_{3} ; \text { coulsonite, } \mathrm{FeV}_{2} \mathrm{O}_{4}\end{array}$ \\
\hline Material found on the quench lines & $\begin{array}{l}\text { Troilite, } \mathrm{FeS} \text {; chromium sulfide, } \mathrm{Cr}_{7} \mathrm{~S}_{8} \text {; magnesioferrite, } \mathrm{MgFe}_{2} \mathrm{O}_{4} \text {; magnetite, } \mathrm{Fe}_{3} \mathrm{O}_{4} \text {; } \\
\text { chromite, } \mathrm{FeCr}_{2} \mathrm{O}_{4}\end{array}$ \\
\hline
\end{tabular}

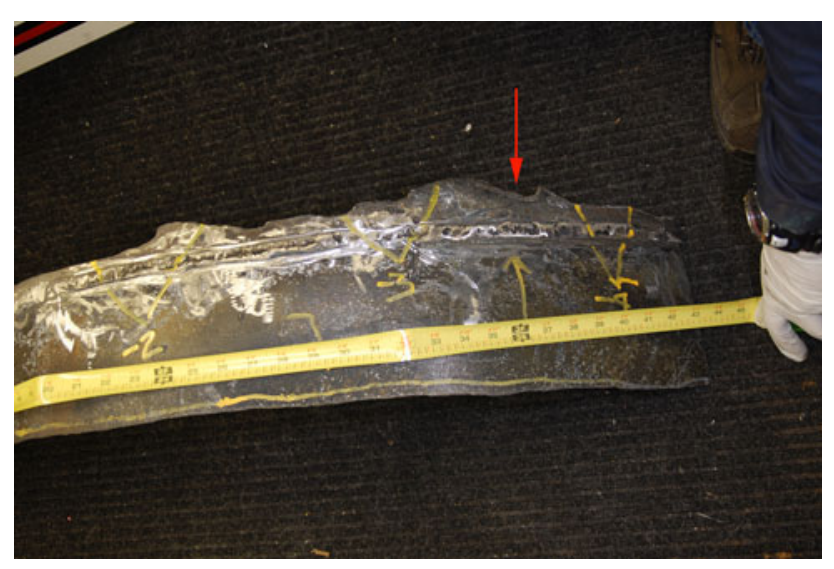

Fig. 9 The circumferential fracture above the top hat, showing locations 3 and 4. The arrow indicates the location shown in Fig. 10

Selected dip tube panels were also removed from just below the top hat and near the bottom, which were examined for physical features that might explain the attack on the dip tube. Wall thicknesses were measured using an ultrasonic thickness gage, and metallurgical cross sections were taken to examine the microstructure for signs of attack, cracking, and overheating. The following features were evaluated on panels removed from above and below the top hat:

- The elongated hole and circumferential fracture above the top hat on the east side,

- The top hat-to-dip tube weld,

- Cracks found above the top hat on the west side,

- Buckling and distortion at various locations above and below the top hat.

The initial failure of the dip tube was found to be an elongated hole on the east side that coincided with a circumferential fracture, which was about $0.5-2.0$ in. above the top hat, shown in Fig. 6. A circumferential fracture extended about 3 feet around the dip tube wall on the east side. The circumferential fracture was irregular, jagged, and thick lipped, and it was located from 0.5 to 2 in. above the top hat, as shown in Fig. 9. This area did not have the excessive buckling that other locations showed.

The circumferential fracture just above the top hat was an indication that the axial stresses were high enough to cause failure of the dip tube. The fracture extended from the longitudinal seam weld on the dip tube toward the east for about 3 feet. The irregular shape indicated that cracks had initiated at multiple locations at different times, as the horizontal cracks were found to be both extended and intersected.

The fracture was typically thick lipped and thinned in only a few locations. The fracture edge thickness ranged from 0.22 to $0.28 \mathrm{in}$. This thick edge indicated that the dip tube fractured in a brittle manner, rather than being thinned by an erosion or corrosion mechanism. Although the metal near the fracture was not excessively thinned, the fracture edge was oxidized and altered by the hot syngas passing over it during the incident. The fracture surface was examined, but no obvious fracture features were discernible because of the surface oxidation. The brittle-like fracture appearance, thick-lipped features, cracks, and the lack of deformation indicated that this location above the top hat lacked ductility.

Various locations along the fracture were examined in detail. Location 1 was just above the top hat-to-dip tube weld, where it coincided with the longitudinal dip tube seam weld. The location of first failure is believed to have occurred in the region that showed the greatest signs of discoloration, which was below the cone plate and baffle that were oxidized and burned away. Between locations 1 and 2, the top hat weld was missing. This is the same location observed in the field where the weld had separated from the dip tube. As its surface had been ground down during the top hat removal after the incident, this region could not be examined.

Location 3 was below the circumferential fracture and about $1 \mathrm{in}$. above the top hat. Some cracks were found at this location. Additional cracks were observed between locations 3 and 4, as shown in Fig. 10. The cracks were cross sectioned to determine the crack morphology. Figures 11 and 12 show secondary cracks that were about 1 in. above the top hat and perpendicular to the circumferential fracture between locations 3 and 4 . These cracks initiated from both the outside and inside surfaces, and extended along the grain boundaries, where many grain boundary precipitates were observed. Although these precipitates were not micro-probe analyzed, the grain boundaries likely were filled with carbides, possibly gamma prime and sigma phases, all indicative of elevated temperature exposure, 


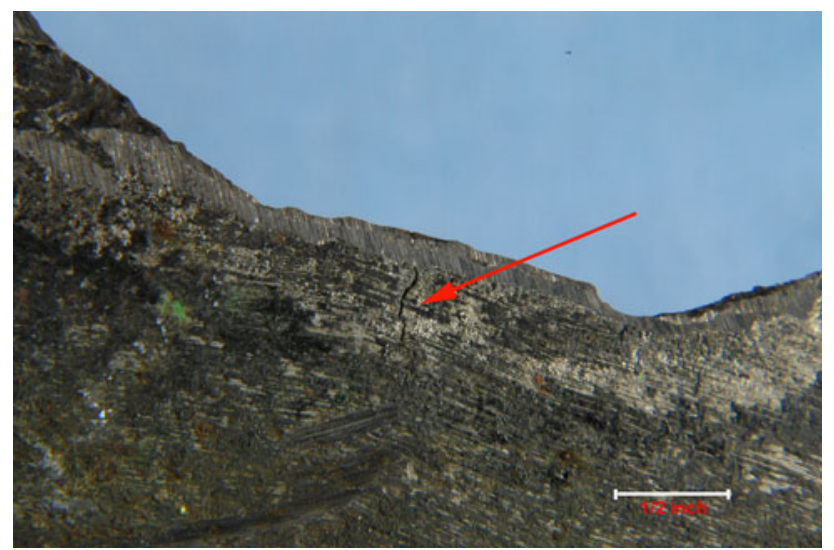

Fig. 10 Close-up of the crack between locations 3 and 4 shown in Fig. 9

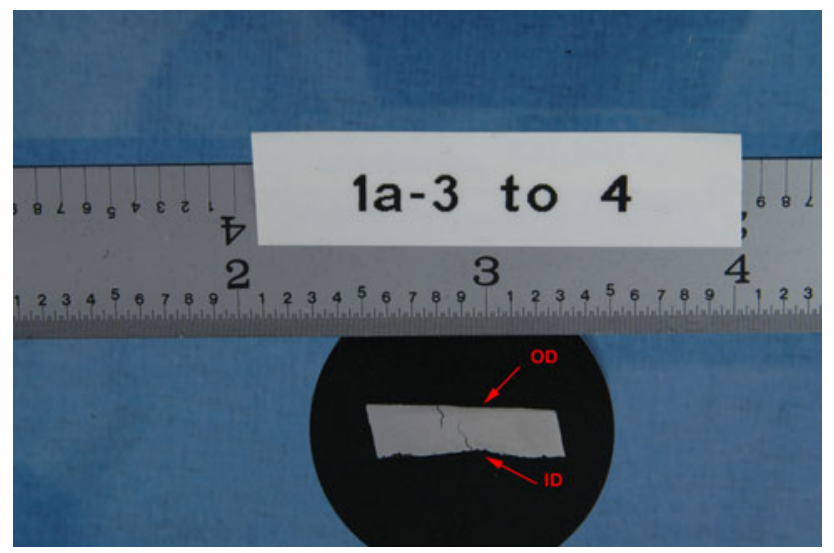

Fig. 11 Macrophotograph of the secondary cracks that were found near the circumferential fracture between locations 3 and 4

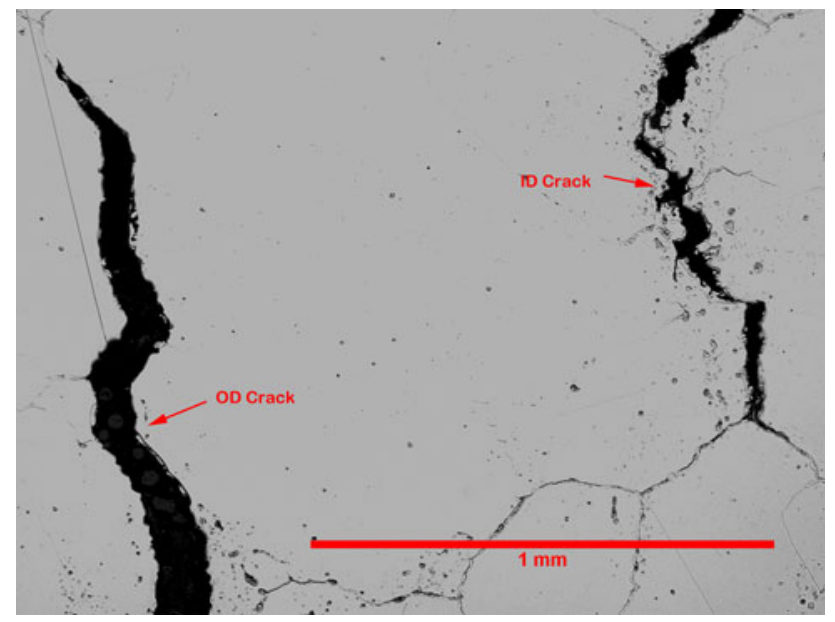

Fig. 12 ID and OD cracks along the grain boundaries between locations 3 and 4

shown in detail in Fig. 13. Similar microcracks were also found on the dip tube from gasifier no. 2 that had not progressed to failure, shown in Fig. 14.

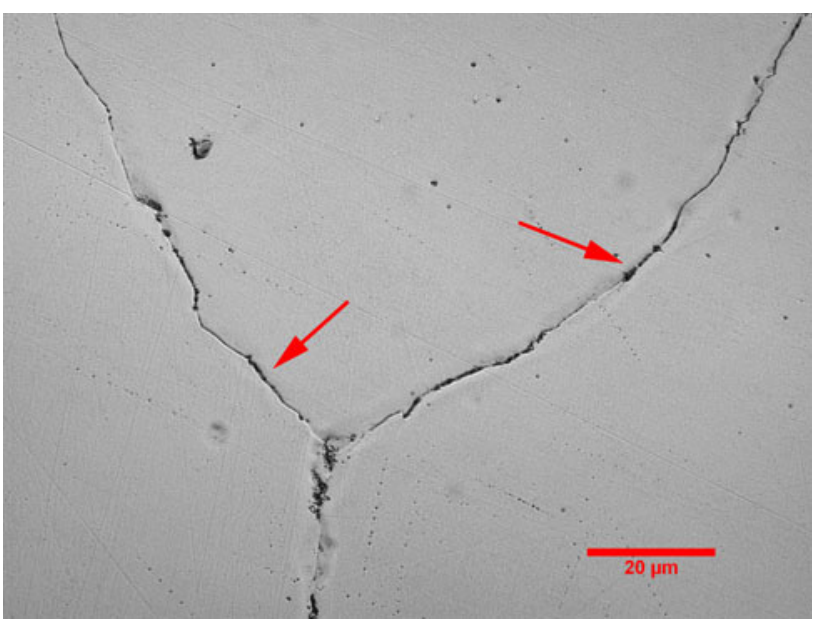

Fig. 13 Carbide precipitates along the grain boundary between locations 3 and 4

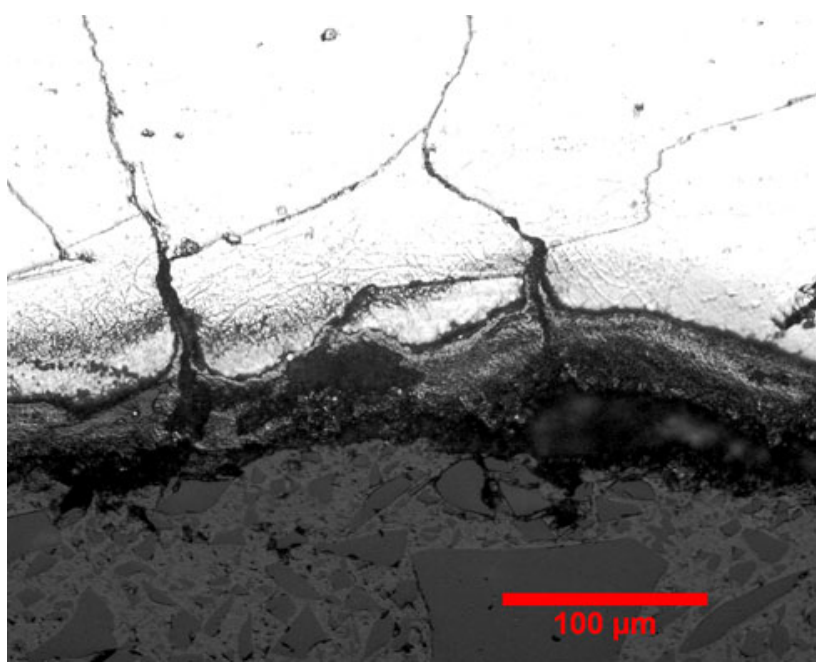

Fig. 14 Photomicrograph of the outside dip tube surface for gasifier no. 2 , showing sulfide products and cracks along the grain boundaries (oxalic acid etched)

These cracks were likely caused by "stress relaxation cracking," which occurs in alloys such as Incoloy 825 operating between 550 and $750{ }^{\circ} \mathrm{C}$ [1,2]. This mechanism is also referred to as "stress-induced cracking," "reheat cracking," or "stress-assisted grain boundary oxidation" (SAGBO). The fracture is often brittle in appearance and occurs in cold worked regions, frequently in the proximity of welds. The cracks are located along grain boundaries where at elevated temperatures fine precipitates can form, causing the grain boundary to lose ductility and crack when strained. Often a nickel-rich filament is found in the grain boundary surrounded by a chromium-enriched oxide layer. One crack location, shown in Fig. 15, had a chromiumenriched zone that surrounded a filament. Typically stress relaxation cracking occurs at hardnesses above HV 200. The original hardness of the Incoloy 825 dip tube ranged 


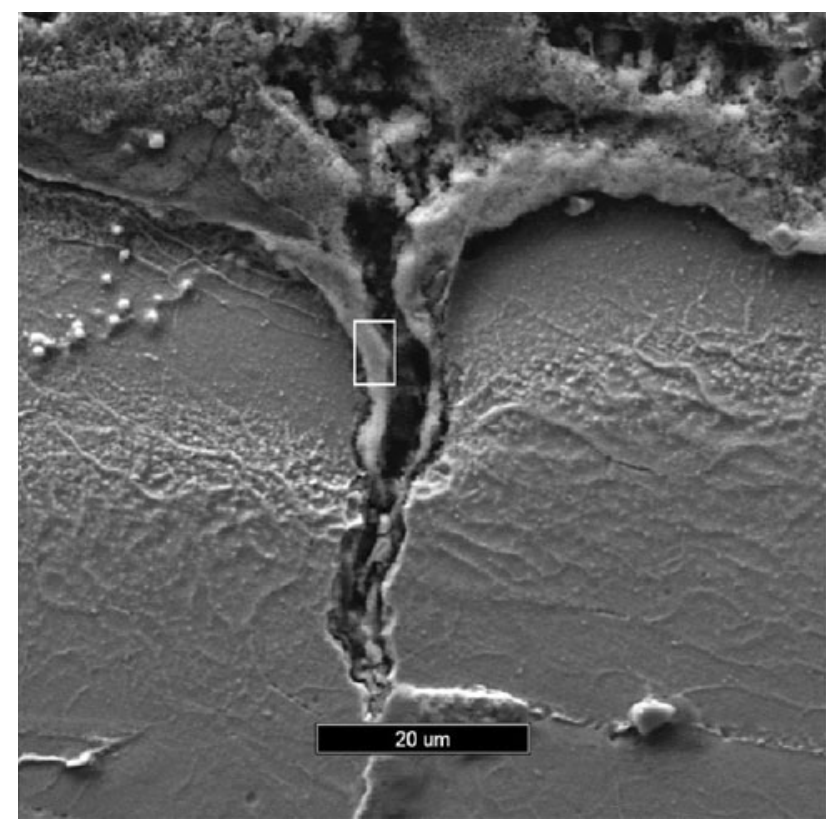

Fig. 15 SEM image of the intergranular crack that had a chromiumenriched zone in the grain boundary

from HV 215 to 227. These observed features supported stress relaxation cracking as the principal failure mechanism for the Incoloy 825 Alloy dip tube.

The dip tube wall temperatures could have been above $550{ }^{\circ} \mathrm{C}$ due to hot syngas on the inside and the lack of cooling on the outside. This could have caused the formation of carbides and precipitates in grain boundaries that would give the material less ductility when stressed and strained.

After the stress relaxation cracks formed, the elongated hole is believed to have developed, and once the through wall elongated hole was present, hot gases could escape into the region outside the dip tube. A metallurgical section through the edge revealed that the Incoloy 825 material had melted. The melting point of Incoloy is about $1,400{ }^{\circ} \mathrm{C}$.

The panel section on the west side of the dip tube had two distinct cracks, one vertical and one horizontal, that were located above the top hat, approximately $180^{\circ}$ away from the large hole on the east side. The vertical crack was about 4 in. above the top hat. The horizontal crack was angled at about $20^{\circ}$ from the horizontal plane, about 3.5 in. above the top hat, as shown in Fig. 7. The wall thickness was reduced to a thickness of about $0.22 \mathrm{in}$. from an original thickness of 0.26 in. The horizontal crack was 1.8-in. long and initiated from the inside surface, shown in Figs. 16 and 17. Although the scale inside the crack was not analyzed, it was likely oxides and sulfides. The crack pattern along the grain boundaries was similar to that observed at the circumferential fracture on the east side, indicating that the stress relaxation cracks occurred before a hole was formed.

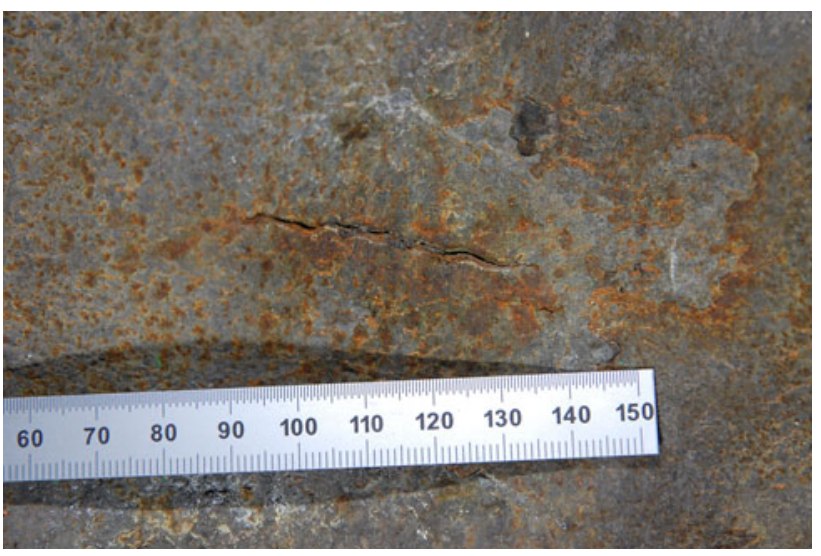

Fig. 16 The ID surface of the west panel showing the horizontal crack

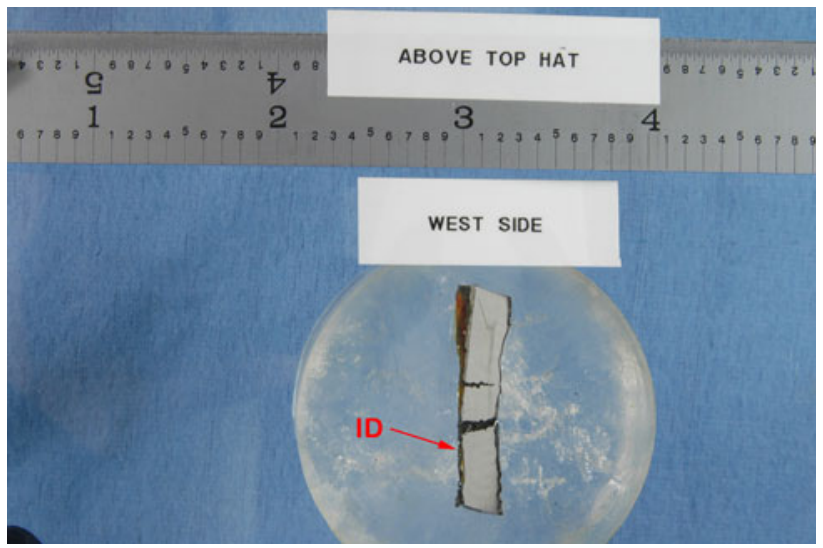

Fig. 17 Cross section through the horizontal crack that initiated from the ID surface

\section{Buckling of the Dip Tube}

Extensive buckling and oxidation were observed at locations all around the dip tube. Distortion and waviness occurred about 18 in. above the top hat. The greatest amount of buckling occurred about 1.5-3.0 in. above the top hat. One obviously buckled location was on the west side, about $120^{\circ}$ away from the large elongated hole. Figures 18 and 19 show a longitudinal section through that buckled area, which revealed wall thinning as well as cracks that extended from the outside surface. Slag had built up on the inside, and the outside had a deposit buildup. The measured wall loss was about 0.10 in.; the wall was thinned from the original wall thickness of $0.26 \mathrm{in}$. to about 0.16 in. Figure 20 shows the surface cracks that initiated from the outside surface and which were filled with scale. Spike-like cracks were present on the outside surface, which were about 0.07 -in. deep. These spike-like cracks were not similar to the grain-boundary cracks seen on the east side; they were probably the result of oxidation 


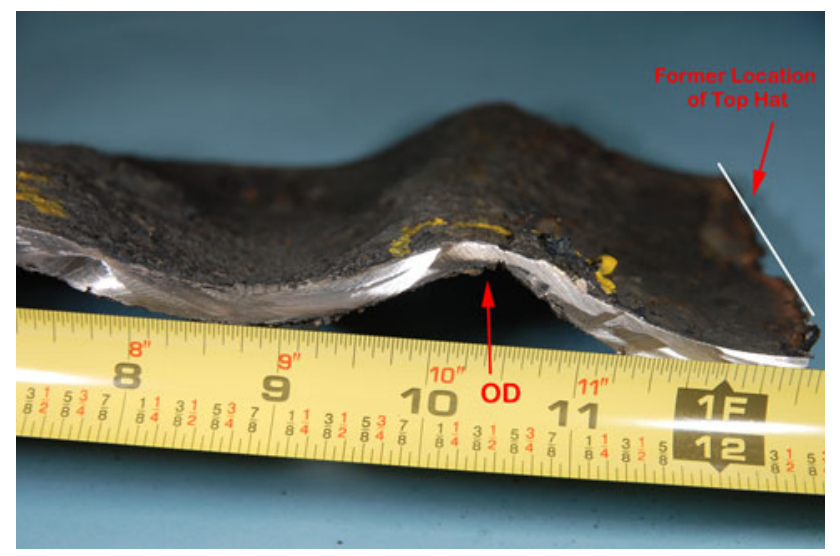

Fig. 18 Longitudinal section through the buckling on the northwest side of the dip tube. The top hat was located at the far right

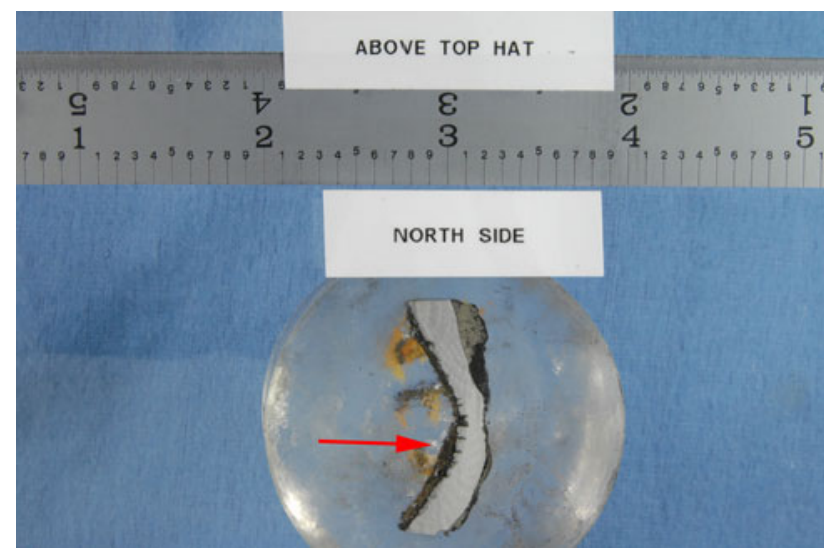

Fig. 19 Longitudinal section showing cracks on the outside of the dip tube. The arrow indicates the outside surface

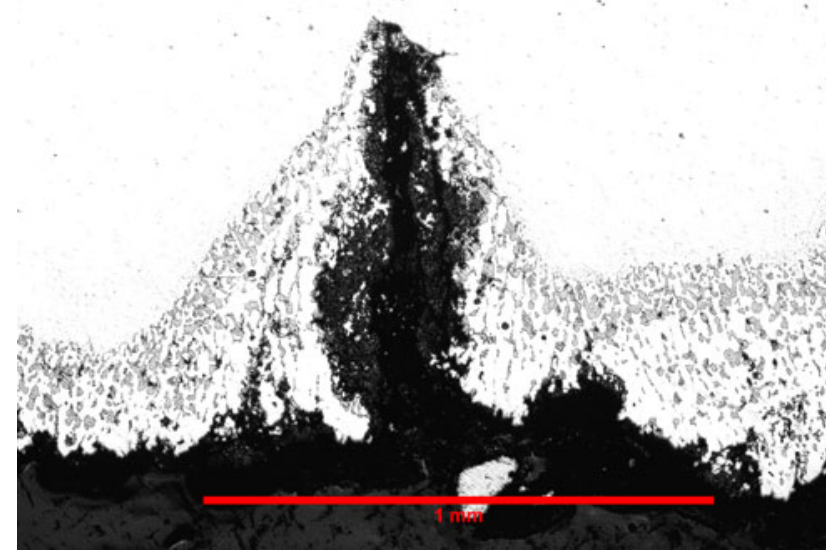

Fig. 20 Photomicrograph of the cracks and oxidation on the outside surface of the dip tube and the elevated temperature that developed after the hole formed in the dip tube. EDS analysis showed that the deposits in the crack contained mostly sulfur. The cracks were on the compression side of the buckle, which is unusual since cracks typically initiate from the tension side.

At elevated temperatures, especially above $540{ }^{\circ} \mathrm{C}$, the ultimate strength and elastic modulus of Incoloy 825 decreases, as shown in Fig. 21 [3]. Buckling occurred in the dip tube due to compression stress exceeding the yield strength of the material, caused by the increase in temperature. Additional mechanical stresses were created by the rigid supports to the top hat. Therefore, the damage to the dip tube indicated that it was exposed to temperatures $>540{ }^{\circ} \mathrm{C}$, but the actual wall temperature could not be determined. Most of the buckling likely occurred during the incident when hot syngas escaped from the dip tube hole on the east side.

\section{Mechanical Testing}

Four samples were taken from the dip tube to determine if the room temperature tensile properties had been affected. Tensile test specimens were prepared and tested in accordance with ASTM A370 (Mechanical Testing of Steel Products). Table 5 shows the tensile test results, which did not reveal significant changes in the room temperature properties. The yield strength of the samples from above the top hat was slightly lower compared to samples from below the top hat, but the yield strength was still close to the typical room temperature properties for Incoloy 825. Although the dip tube was exposed to elevated temperatures above the top hat, the wall material did not show a loss of ductility at room temperature.

Incoloy 825 can be supplied in either the solution annealed or the stabilized condition, where it would have the best resistance to "stress relaxation cracking." Such stabilization treatment requires that the material be heat treated in the temperature range of $940-955^{\circ} \mathrm{C}$. It was not verified whether the dip tube material was supplied in a stabilized condition in order to have had a greater resistance to the formation of carbides and precipitates.

\section{Cone Plate Failure Analysis}

As a result of the hole in the dip tube, hot syngas impinged on the baffle and the bottom side of the cone plate. The 1in. thick cone plate, which separated the combustion chamber from the quench chamber and supported the refractory, was deteriorated and completely missing from the area above the hole in the dip tube. Figure 22 shows 
Fig. 21 Stress versus temperature curves for Incoloy 825 . Notice the decrease in ultimate strength and elongation at temperatures $>540{ }^{\circ} \mathrm{C}$. Above $590{ }^{\circ} \mathrm{C}$, the elongation increases rapidly with temperature

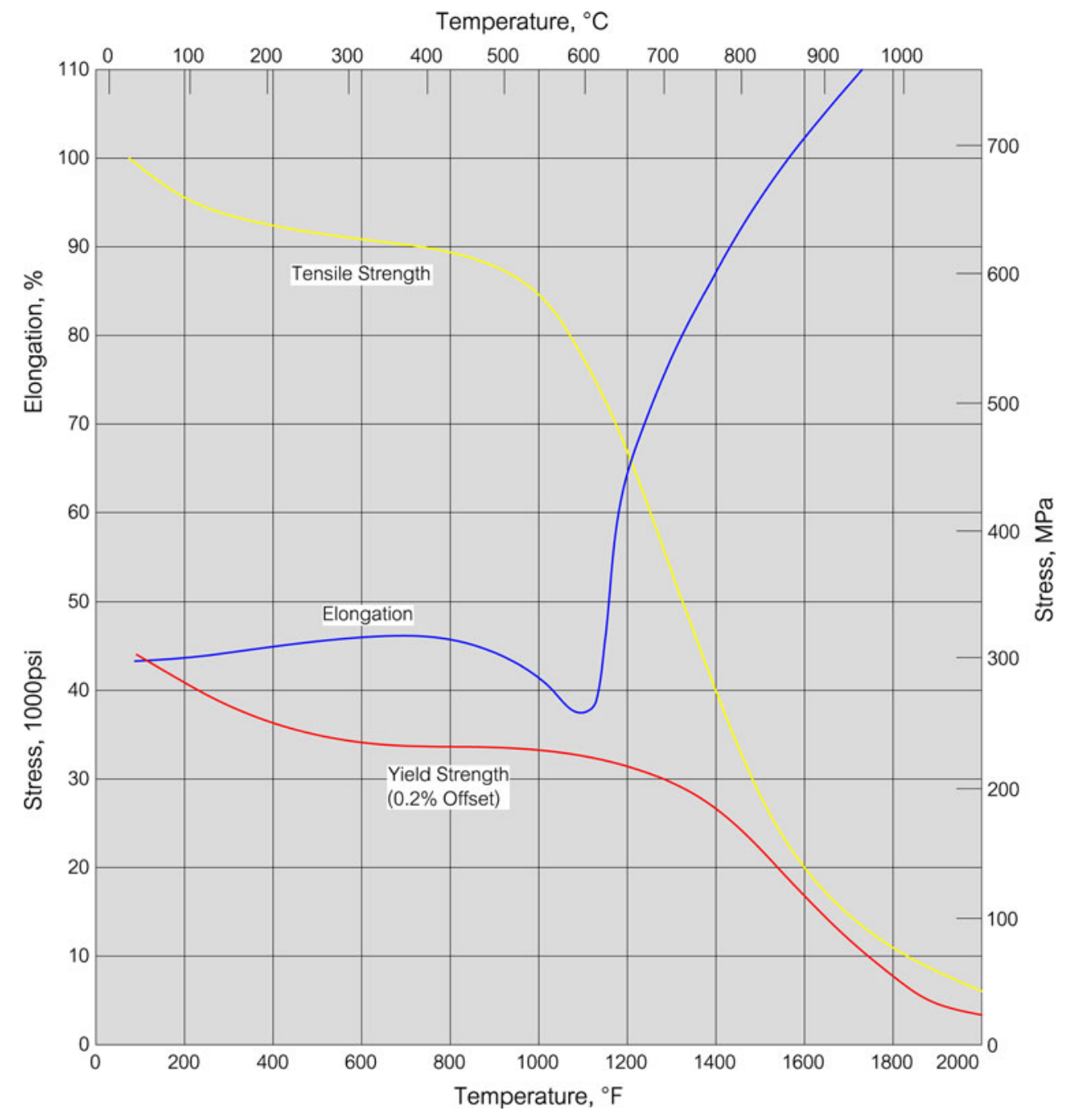

Table 5 Tensile test results for the Incoloy 825 dip tube

\begin{tabular}{|c|c|c|c|}
\hline Specimen ID & $\begin{array}{l}\text { Ultimate tensile } \\
\text { strength (ksi) }\end{array}$ & $\begin{array}{c}\text { Yield } \\
\text { strength (ksi) }\end{array}$ & Elongation $(\%)$ \\
\hline T1: Dip tube below the water line about 2 feet above the bottom & 98.5 & 53.0 & 60 \\
\hline T2: Dip tube below top hat in a distorted region & 102.0 & 61.5 & 52 \\
\hline T3: Dip tube above top hat on the west side in distorted region & 93.5 & 50.5 & 56 \\
\hline T4: Dip tube above the top hat on the east side in distorted region & 95.5 & 47.3 & 62 \\
\hline Typical Incoloy 825 & 96.0 & 49.0 & 45 \\
\hline
\end{tabular}

part of the remaining cone material removed for characterization. Metallurgical sections through this cone plate material indicated that the damage was predominately due to high-temperature oxidation and erosion. In addition, there were isolated regions that showed evidence of incipient melting, Fig. 23. These regions were also hardened to Rockwell HRC 50, probably from being heated to elevated temperature and then rapidly cooled.
For this particular steel $\left(1 \frac{1 / 4}{\mathrm{Cr}-1 / 2} \mathrm{Mo}\right)$, incipient melting occurs at about $1,420{ }^{\circ} \mathrm{C}$, meaning that the syngas must have been significantly hotter. The melting observed on the Incoloy 825 dip tube also indicated that the hot gas was significantly hotter than $1,425{ }^{\circ} \mathrm{C}$. These findings are consistent with the identification of the deposits found on the top hat resulting from melting and oxidation of the cone plate. 


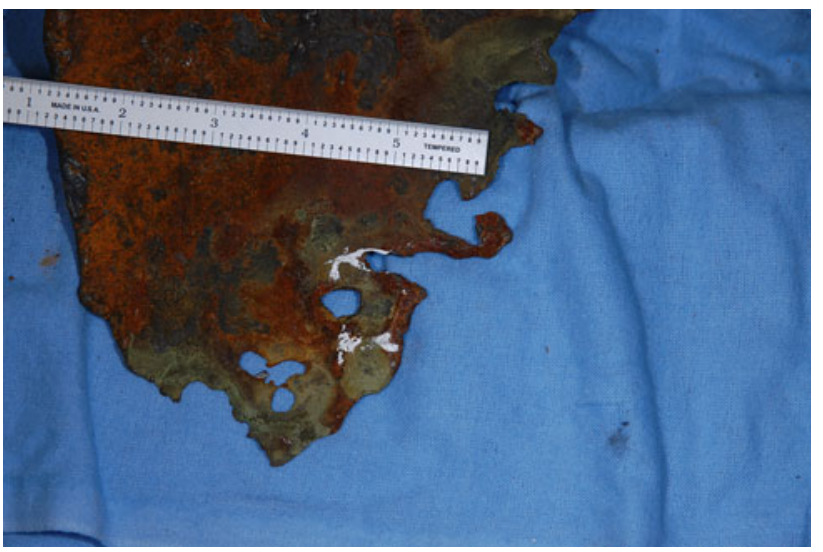

Fig. 22 Oxidized and burned cone material

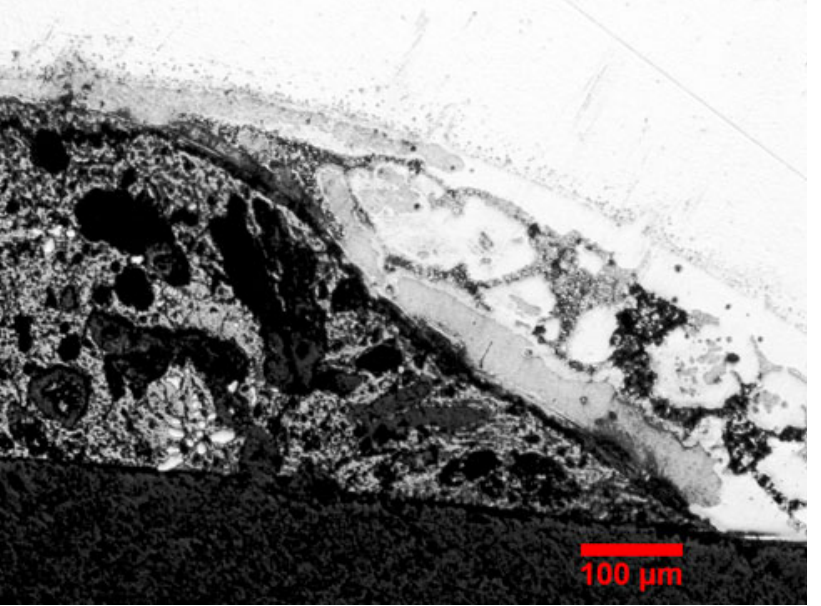

Fig. 23 Photomicrograph of cross-sectioned cone plate material showing incipient melting (unetched)

\section{Shell Wall Failure Analysis}

As a result of the hole in the east side of the dip tube, hot syngas impinged not only on the baffle and cone plate, but also on the gasifier shell wall. The 4.65-in. thick vessel shell wall failed due to elevated temperature stress rupture (creep failure), which was indicated by the extensive bulging, microcracking, and void formation on its outside surface. Figure 24 shows the stress rupture voids near the outside surface. Microstructural assessment of the shell wall indicated the degeneration of the typical microstructure phase pearlite and in some locations the formation of spheroidized cementite. Figure 25 shows the pearlite and ferrite structure from a location that did not get as hot, but still had the same lamellar colonies; Fig. 26 shows complete spheroidization. This change in microstructures in $1 \frac{1 / 4}{4}$ chromium steel typically occurs only at elevated temperatures, but below the critical transformation temperature,

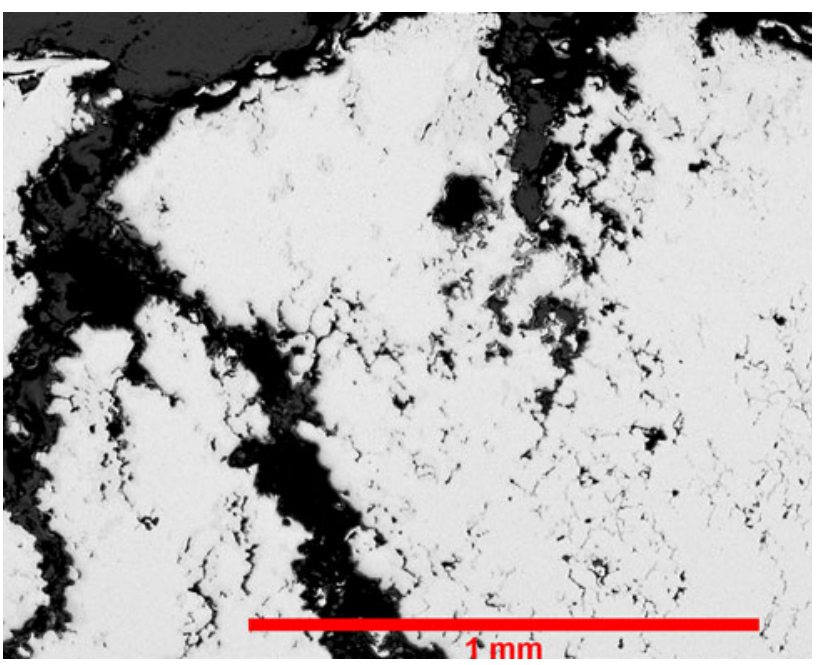

Fig. 24 Photomicrograph of the outside surface of the shell wall near the rupture location, showing the stress rupture voids (unetched)

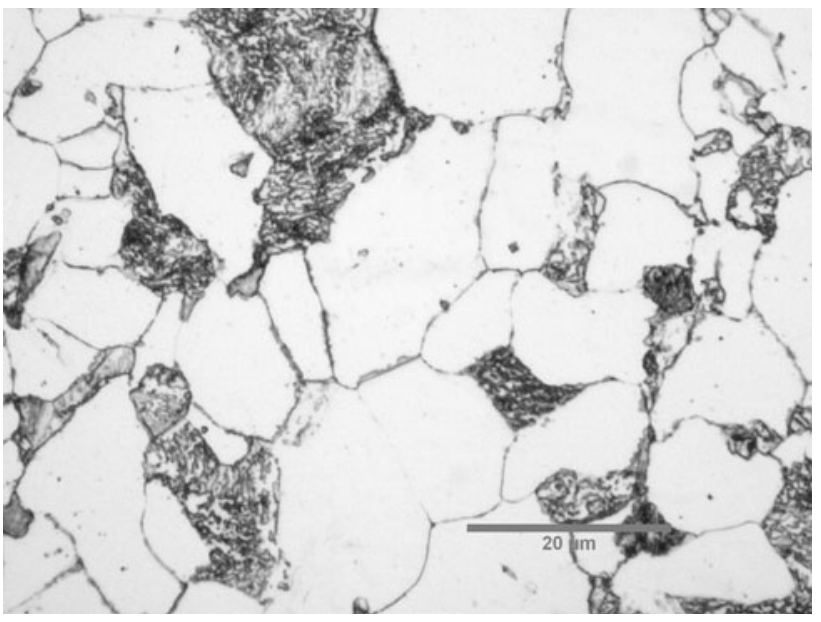

Fig. 25 Photomicrograph of the outside surface of the shell wall, about $11 \mathrm{in}$. above the rupture, showing pearlite colonies (nital etched)

which is near $720{ }^{\circ} \mathrm{C}$. Complete phase transformation can occur above this temperature. There were no signs of phase transformation except where the hot gases escaped, thus it is unlikely that the shell was heated above $760{ }^{\circ} \mathrm{C}$ before the failure occurred.

In order for the shell to exhibit a creep failure, the wall had to be heated to temperatures greater than its normal operating temperature. Typically, the maximum operating temperature for $1 \frac{1 / 4}{\mathrm{Cr}-1 / 2}$ Mo steel is about $550{ }^{\circ} \mathrm{C}$ [4]. At temperatures greater than this, failure will occur rapidly. Visual examination showed that hot syngas escaped through the hole in the dip tube and impinged on the cone plate and baffles, causing them to oxidize and melt. This hot gas flow also heated the shell wall to near $700{ }^{\circ} \mathrm{C}$, where it began to soften, bulge, and fail due to stress rupture. 


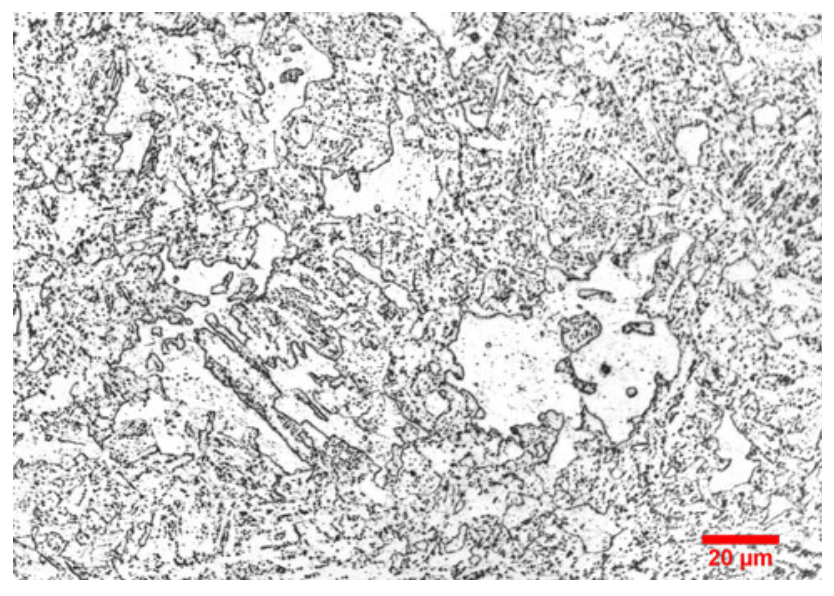

Fig. 26 Photomicrograph near inside surface of the shell wall, about 19 in. below the rupture, showing the spheroidized structure (nital etched) focus

Thermal stresses played a major role in causing the shell failure, rather than just stress from internal pressure. This explains why the main failure cracks were horizontal (transverse) rather than axial. The affect of thermal stresses was also indicated by the presence of scale-filled cracks found in the stainless steel liner on the vessel wall.

The following question was asked: What was the approximate temperature and time of exposure that caused the shell to rupture? To address this question, the time for the shell wall to fail at elevated temperatures was estimated by calculating the approximate shell stress at its internal pressure and comparing this stress and exposure temperature to the stress rupture curve for a comparable $1 \frac{1 / 4}{\mathrm{Cr}-1 / 2}$ Mo steel. This calculation is presented in the "Appendix." The metallurgical assessment of the shell microstructure indicated that the shell wall temperature was less than about $720^{\circ} \mathrm{C}$. This implies that the shell was gradually heated over time. An exposure time was estimated from the process thermocouple data, which showed higher than typical operating temperature for a total of about $13 \mathrm{~h}$. Based on the metallurgical assessment, the stress rupture curve, and the shell stress calculations, the temperature required for rupture to occur in $13 \mathrm{~h}$ was approximately $690 \pm 15^{\circ} \mathrm{C}$.

The investigation concluded that impingement of hot combustion gases (much hotter than $690{ }^{\circ} \mathrm{C}$ ) escaping through the dip tube hole onto the shell wall caused the stress rupture failure of the gasifier no. 1 vessel.

\section{Conclusions}

This gasifier incident occurred because a hole formed in the dip tube wall, allowing hot syngas to directly escape without passing through the quench, causing overheating of the vessel shell wall. The dip tube, a critical part of the syngas quench process, had been modified with the addition of a top hat that altered the flow dynamics, mechanical support, and external cooling of the dip tube, leading to failure of the Incoloy 825 dip tube wall above the top hat and ultimately, the failure of the gasifier vessel.

The metallurgical assessment found that the dip tube had a brittle-like circumferential fracture above the top hat, which resulted in the formation of oxidation, scaling, and stress-assisted grain boundary cracks. The dip tube cracks and fractures can best be explained by a phenomenon known as "stress relaxation cracking," which occurs in austenitic stainless steels such as the Incoloy Alloy 825 operating between 550 and $750{ }^{\circ} \mathrm{C}$. At these temperatures, fine precipitates form, which in turn causes the grain boundaries to lose ductility, causing the metal to crack along the grain boundaries when strained. Widespread degradation of the dip tube wall was observed on all sides above the top hat, indicating that the phenomenon had not just occurred at an isolated location.

Hot syngas escaped from the normal flow to the quench through the hole in the dip tube wall, overheating and oxidizing the 1-in. thick cone plate that separated the combustion chamber from the quench chamber. The syngas also impinged on the 4.65 -in. thick, $1 \frac{1 / 4}{4} \mathrm{Cr}-1 / 2$ Mo steel shell wall of the pressure vessel. The shell wall overheated, softened, bulged, and then failed due to stress rupture. Thermal stresses in the thick wall plate played a larger role than stress from the operating pressure, as shown by the failure cracks that were transverse rather than along the axis of the vessel. Based on the metallurgical assessment, data and calculations for stress rupture, the average shell wall temperature necessary for failure was approximately $690 \pm 25^{\circ} \mathrm{C}\left(1,275 \pm 25^{\circ} \mathrm{F}\right)$ at about $13 \mathrm{~h}$, the estimated duration that the gasifier operated at higher than normal temperature.

\section{Recommendations}

Based on the results of this investigation, the following items may be considered for future operational and design concerns regarding gasifiers. These recommendations may be evaluated based upon cost, feasibility, and redundancy of designs. These recommendations are not intended as a comprehensive list, but may provide partial guidance for safe operation of gasifiers.

- Install and monitor temperature sensors at several select locations to give better measurement of normal and abnormal temperatures for the vessel skin and gas temperatures in the gasifier. 
- If Incoloy 825 is used for components, such as the dip tube, specify that it be thermally stabilized once any fabrication, cold working, or welding have been completed.

- Provide sufficient margin in original design and subsequent modifications to account for the effects of temperature variations, mechanical stresses, and water and gas flow dynamics.

- Include consideration of stress relaxation cracking as a potential failure mechanism for both austenitic steels and nickel-chromium alloys, such as Incoloy 825, in future process hazard analyses (PHA) and design reviews.

\section{Appendix: Stress Rupture Lifetime Estimates for the Shell Wall}

The stress rupture lifetime of the shell to failure under various conditions was predicted using the estimated stress and exposure temperature. The estimated stress and exposure shell wall temperature were compared to the stress rupture curve, shown in Fig. 27, for a comparable $1 \frac{1 / 4}{\mathrm{Cr}-}$ $1 / 2$ Mo steel [5]. Shell wall temperatures of 1,200, 1,300, and $1,400{ }^{\circ} \mathrm{F}\left(650,705\right.$, and $\left.760{ }^{\circ} \mathrm{C}\right)$ were selected to determine the approximate time to failure at an assumed stress based on the design calculation estimates. The following assumptions were made:

- The stress rupture curve in Fig. 27 for $1 \frac{1}{4} \mathrm{Cr}-1 / 2 \mathrm{Mo}$ steel tube was applicable to the shell wall.

- The estimated stress on the shell wall was the upper bound of the internal pressure stress.
The thermal stresses that contributed to the failure were not estimated.

\section{Estimate of the Wall Stress at Operating Pressures During Temperature Excursions}

According to the process history, there were two temperature excursions higher than typical in the quench chamber. On the day of the incident, the temperature was above the normal operating point for about $8 \mathrm{~h}$ and $35 \mathrm{~min}$. On the previous day that the gasifier was operated, the temperature was above normal for about $4 \mathrm{~h}$ and $35 \mathrm{~min}$, giving a total time of operation at higher than normal temperature of about $13 \mathrm{~h}$. Based on the metallurgical assessment, the actual shell wall temperature was likely above $1,200{ }^{\circ} \mathrm{F}$ but below $1,330{ }^{\circ} \mathrm{F}$. The pressure during these excursions was about 700 psig on the day of the incident and about 900 psig previously. These two pressures were used to estimate the stress on the shell.

The ASME Section VIII Division 11995 Edition formula was used to calculate the hoop stress at these two pressures. This formula was used in the original design calculation of the maximum allowable pressure and wall thickness required for this vessel. The equation is:

$P=S \cdot E \cdot t /(R+0.6 \cdot t)$

where $P$ is the internal pressure (900 and $700 \mathrm{psig}$ ), $S$ is the outside stress on the shell wall (to be calculated, ksi), $E$ is the joint efficiency (set equal to 1 ), $t$ is the wall thickness (4.65 in.), and $R$ is the radius of the vessel (63.25 in.).

Using the above equation, the wall stresses $(S)$ at 900 and 700 psig were calculated to be 12.78 and $9.94 \mathrm{ksi}$,
Fig. 27 Stress rupture curve for $11 \frac{4}{\mathrm{Cr}}-1 / 2$ Mo steel

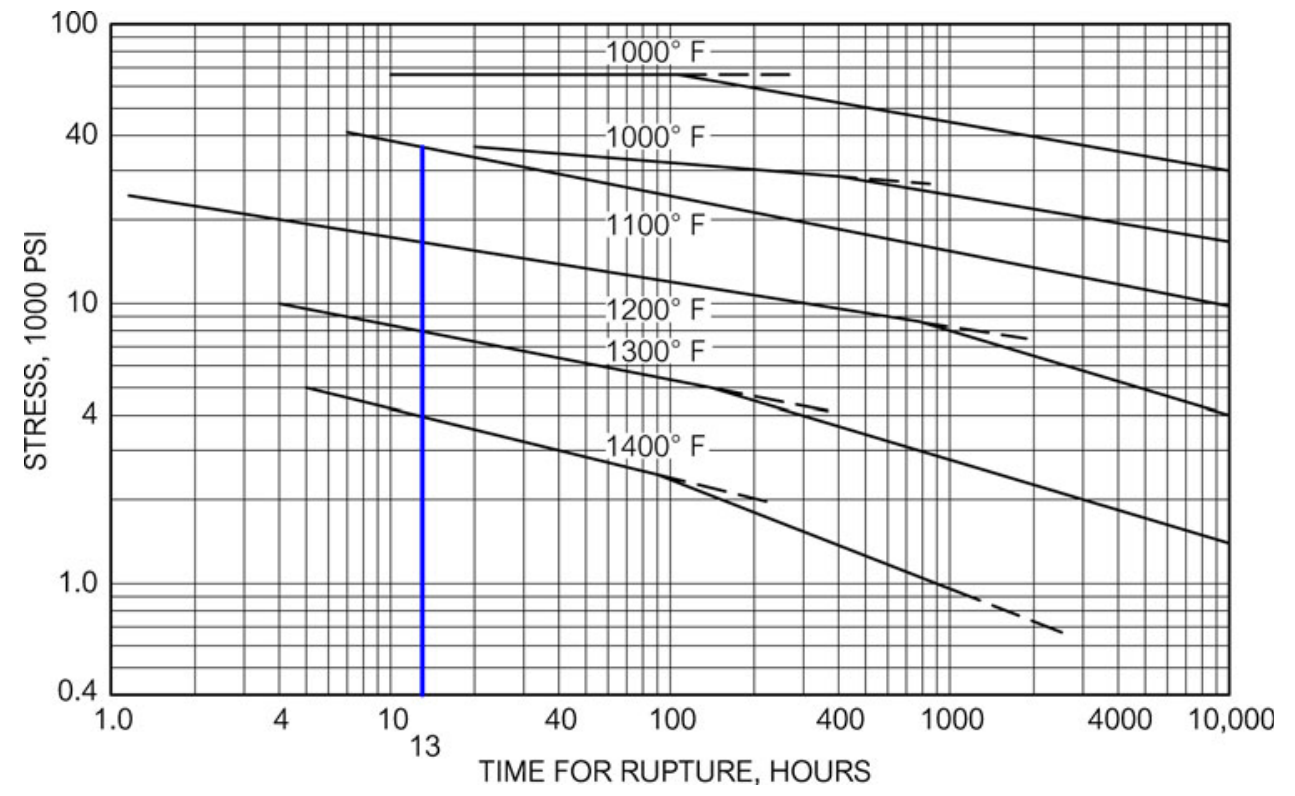


Table 6 Stress rupture time estimates

\begin{tabular}{|c|c|c|c|c|c|c|c|}
\hline \multirow[b]{2}{*}{ Condition } & \multirow[b]{2}{*}{ Temp $\left({ }^{\circ} \mathrm{F}\right)$} & \multicolumn{2}{|c|}{ Internal stress } & \multicolumn{2}{|c|}{ Wall stress } & \multirow{2}{*}{$\begin{array}{c}\text { Predicted } \\
\text { failure time }(\mathrm{h})\end{array}$} & \multirow{2}{*}{$\begin{array}{c}\text { Possible } \\
\text { exposure time }(\mathrm{h})\end{array}$} \\
\hline & & $\mathrm{MPa}$ & psig & $\mathrm{MPa}$ & ksi & & \\
\hline Condition 1 & 1,200 & 6.2 & 900 & 88 & 12.78 & 60 & 4.5 \\
\hline Condition 2 & 1,300 & 6.2 & 900 & 88 & 12.78 & $<1$ & 4.5 \\
\hline Condition 3 & 1,400 & 6.2 & 900 & 88 & 12.78 & $<0.1$ & 4.5 \\
\hline Condition 4 & 1,200 & 4.8 & 700 & 68 & 9.94 & 300 & 8.5 \\
\hline Condition 5 & 1,300 & 4.8 & 700 & 68 & 9.94 & 4 & 8.5 \\
\hline Condition 6 & 1,400 & 4.8 & 700 & 68 & 9.94 & $<0.4$ & 8.5 \\
\hline
\end{tabular}

respectively. These wall stress values were used to estimate the time to failure at the selected temperatures, as shown in Table 6, using the stress rupture curve in Fig. 27.

\section{Stress Rupture Results}

The stress rupture lifetime estimates based on the stress rupture curve and the stress estimates indicated the following:

- The predicted time for failure of the shell wall at $1,200{ }^{\circ} \mathrm{F}$ was greater than the exposure time, so the average temperature was probably $>1,200^{\circ} \mathrm{F}$, which is consistent with the metallurgical results.

- The predicted time for failure at $1,400{ }^{\circ} \mathrm{F}$ was $<0.5 \mathrm{~h}$, which is shorter than the actual exposure time. This is consistent with the metallurgical results indicated that the wall temperature was $<1,400{ }^{\circ} \mathrm{F}$.

- The predicted time for failure at $1,300{ }^{\circ} \mathrm{F}$ was about $4 \mathrm{~h}$, which is about one-third of the total exposure time of $13 \mathrm{~h}$. Therefore, the average exposure temperature was probably $<1,300^{\circ} \mathrm{F}$.
- Figure 27 does not provide rupture curves between 1,200 and $1,300{ }^{\circ} \mathrm{F}$; the predicted time for failure changes rapidly in this range. The actual average shell wall temperature was probably between 1,250 and $1,300{ }^{\circ} \mathrm{F}$.

\section{References}

1. Shoemaker, L.E., Smith, G.D., Baker, B.A., Poole, J.M.: Fabricating nickel alloys to avoid stress relaxation cracking. In: NACE Corrosion 2007 Conference and Expo, NACE Paper No. 07421. Special Metals Corporation (2007)

2. Wortel, H.V.: Control of relaxation cracking in austenitic high temperature components. In: NACE Corrosion 2007 Conference and Expo, NACE Paper No. 07423. TNO Science and Industry (2007)

3. Inco Alloys International: Product Literature for Incoloy Alloy 825, p. 3 (1987)

4. Benac, D.J., Swaminathan, V.P.: Elevated-temperature life assessment for turbine components, piping and tubing. In: ASM Handbook, vol. 11, Failure Analysis and Prevention, ASM International, Materials Park, OH, p. 304 (2002)

5. The Timken Roller Bearing Company: Digest of Steels for High Temperature Service, 6th edn. p. 26 (1957) 